\title{
Poly(L-lactide) nanocomposites containing octaglycidylether polyhedral oligomeric silsesquioxane: Preparation, structure and properties
}

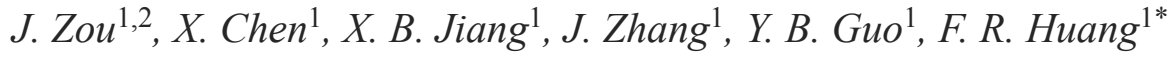 \\ ${ }^{1}$ China Key Laboratory for Specially Functional Polymeric Materials and Related Technology of the Ministry of \\ Education, School of Materials Science and Engineering, East China University of Science and Technology, Shanghai \\ 200237, PR China \\ ${ }^{2}$ School of Materials Science and Engineering, Jiangsu University of Science and Technology, Zhenjiang, Jiangsu 212003, \\ PR China
}

Received 13 November 2010; accepted in revised form 25 January 2011

\begin{abstract}
Poly(L-lactide)s (PLLA) tethered with octaglycidylether polyhedral oligomeric silsesquioxane (OPOSS) with contents of $0.02-1.00 \mathrm{~mol} \%$ were successfully prepared by solution ring-opening polymerization of L-lactide in the presence of $\mathrm{Sn}(\mathrm{Oct})_{2}$ catalyst. Fourier transform infrared (FTIR) and proton nuclear magnetic resonance ${ }^{1} \mathrm{H}-\mathrm{NMR}$ spectroscopic techniques confirm the formation of secondary hydroxyls due to the reaction between PLLA main chains and OPOSS cages. X-ray analyses prove that the presence of OPOSS does not alter the packing structure of PLLA chain in the crystals but enhances the crystallinity of PLLA hybrids. PLLA/PLLA-OPOSS nanocomposites with PLLA-OPOSS contents of 1-30 wt $\%$ were prepared by solution-mixing of the neat PLLA polymer with various contents of the PLLA-OPOSS hybrid with $0.50 \mathrm{~mol} \%$ OPOSS. It is found that the glass transition temperature of the PLLA/PLLA-OPOSS nanocomposites remains the same as that of pristine PLLA and the thermooxidative stability of the nanocomposites is improved with the PLLA-OPOSS content of 1-20 $\mathrm{wt} \%$, as compared to that of the neat PLLA polymer. PLLA/PLLA-OPOSS nanocomposites, except for PLLA/PLLA-OPOSS ${ }^{1}$, has higher crystallization rate at $120^{\circ} \mathrm{C}$. The nucleation density increases with increase in the content of PLLA-OPOSS.
\end{abstract}

Keywords: nanocomposites, poly(L-lactide), octaglycidylether POSS, hybrid PLLA

\section{Introduction}

Recently, people have paid much attention to polylactide (PLLA) from annually renewable resources due to its good biodegradability, high mechanical strength, excellent shaping and molding properties [1-4]. However, PLLA exhibits some disadvantages, such as low thermooxidative stability and slow crystallization rate, which greatly limit its application. Therefore, several methods, including blending with other polymers, copolymerization with other monomers, have usually been used to control the properties of PLLA [5-8]. The addition of nanoparticles such as nanoclay and carbon nanotubes into PLLA is also an attractive way to improve the performance of PLLA [9-14].

As for nanoparticles, more and more attention has been paid to polyhedral oligomeric silsesquioxanes (POSS) due to their inorganic-organic hybrid nature in the last decade [15-19]. POSS molecules possess a cage-like siloxane structure with a size ranging from 1 to $3 \mathrm{~nm}$ and are surrounded by eight $R$ groups $\left(\mathrm{RSiO}_{1.5}\right)$, where $\mathrm{R}$ can be various types of organic groups, one or more of which is reactive or polymerizable [20]. POSS molecules can be easily

\footnotetext{
${ }^{*}$ Corresponding author, e-mail: fhuanglab@ecust.edu.cn
} (c) BME-PT 
incorporated into polymer systems through blending, grafting or copolymerization $[15,16]$. For example, several polymers, such as HDPE [21], PP [22], epoxy [23-26], PMMA [27-30], PU [31, 32], PET [33-35] and PC [36], have been blended with POSS. It has been reported that PLLA/POSS nanocomposites have enhanced crystallization rate, improved mechanical properties and accelerated hydrolytic degradation as compared with pristine PLLA [19]. PLLA-POSS hybrids were synthesized via the ringopening polymerization of L-lactide with 3-hydroxypropylheptaisobutyl POSS. Then PLLA/PLLAPOSS nanocomposites were made by blending PLLA with PLLA-POSS hybrids in solution and had exhibited improved thermal and thermooxidive degradation properties, high crystallization rates and crystallinities [37].

In this work, PLLA-OPOSS hybrids are synthesized by solution ring-opening polymerization of Llactide with octaglycidylether POSS as an initiator in the presence of a stannous (II) octoate [ $\left.\mathrm{Sn}(\mathrm{Oct})_{2}\right]$ catalyst. PLLA-OPOSS hybrids are introduced into neat PLLA to prepare PLLA/PLLA-OPOSS nanocomposites. The structure of the synthesized PLLAOPOSS hybrids are characterized by Fourier transform infrared spectroscopy (FTIR), ${ }^{1} \mathrm{H}$ nuclear magnetic resonance spectroscopy ( $\left.{ }^{1} \mathrm{H}-\mathrm{NMR}\right)$, and $\mathrm{X}$-ray diffraction analysis. The thermooxidative stability, isothermal crystallization behavior and the spherulitic morphology of the PLLA/PLLA-OPOSS nanocomposites are investigated by thermogravimetric analysis (TGA), differential scanning calorimetry (DSC), optical polarimetry and polarizing optical microscope, respectively.
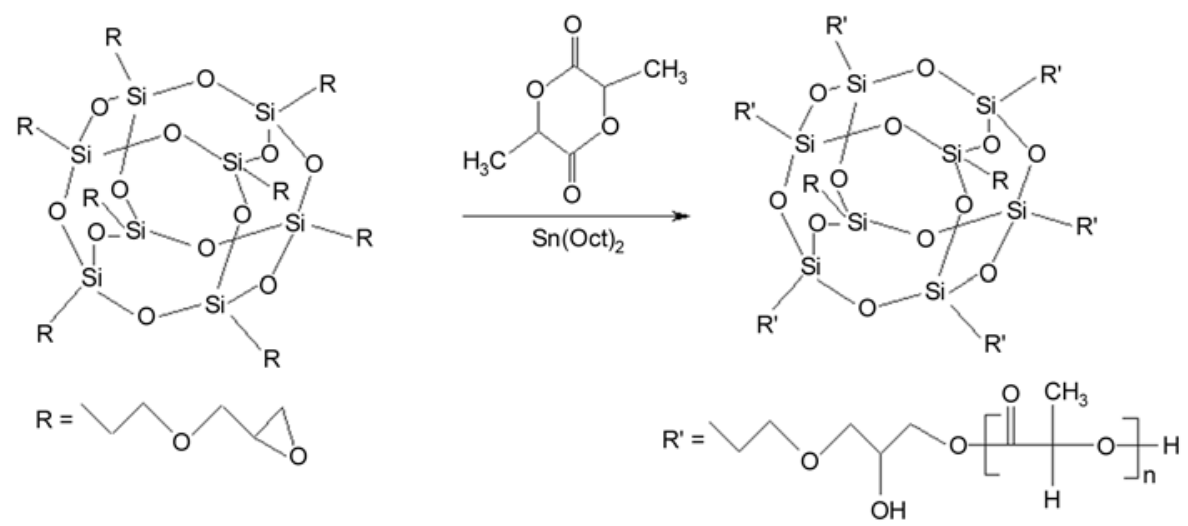

Figure 1. Scheme for synthesis of PLLA-OPOSS hybrids

\section{Experimental}

\subsection{Materials}

L-lactide ( $99.8 \%$, prepared by our laboratory) was used as the monomer for solution ring-opening polymerization. Octaglycidylether POSS (Product name: OPOSS) was purchased from Hybrid Plastics Inc, USA. Sn(Oct) $)_{2}$ (Sigma-Aldrich, USA) was adopted as a catalyst for the solution ring-opening polymerization of L-lactide. PLLA (trade name 4032D, number-average molecular weight $\left(M_{\mathrm{n}}\right)$ $3 \cdot 10^{4} \mathrm{~g} / \mathrm{mol}$ ) was purchased from Nature Works Co. Ltd., USA.

\subsection{Synthesis of PLLA-OPOSS hybrids}

Octaglycidylether POSS (0.02-1.00 mol\%) and Llactide were dissolved into xylene in a flask and heated to $130^{\circ} \mathrm{C}$ under an atmosphere of dry nitrogen, and then $0.1 \mathrm{wt} \% \mathrm{Sn}(\mathrm{Oct})_{2}$ as catalyst was added into the flask. The mixtures were magnetically stirred at $130^{\circ} \mathrm{C}$ for $8 \mathrm{~h}$, then precipitated into excess methanol, and filtrated. The overall reaction scheme is shown in Figure 1. The final products were purified by dissolving in chloroform and precipitating in methanol. Finally, the products were dried in vacuo at $50^{\circ} \mathrm{C}$ for $24 \mathrm{~h}$. The products are named PLLA-OPOSSx hybrids, where the subscript-denotes the molar percentage of OPOSS to Llactide.

\subsection{Preparation of PLLA/PLLA-OPOSS nanocomposites}

For the preparation of PLLA/PLLA-OPOSS nanocomposites, the mixture ( $3 \mathrm{~g})$ of PLLA and PLLAOPOSS 0.50 hybrid was dissolved in chloroform with vigorous stirring. The content of $1-30 \mathrm{wt} \%$ 
PLLA-OPOSS ${ }_{0.50}$ hybrids were adopted for the PLLA/PLLA-OPOSS nanocomposites. The mixed solutions were poured into excess methanol, and the precipitates were filtered. Then, the PLLA/PLLAOPOSS filtrates were dried in vacuo at $50^{\circ} \mathrm{C}$ for $24 \mathrm{~h}$. The nanocomposites are named PLLA/PLLAOPOSS ${ }^{y}$, where $y$ represents the weight percentage of PLLA-OPOSS $\mathrm{S}_{0.50}$.

\subsection{Testing and characterization}

The ${ }^{1} \mathrm{H}-\mathrm{NMR}$ measurements were carried out on a $400 \mathrm{MHz}$ NMR spectrometer (Bruker AVANCE II, Switzerland) for characterization of chemical structures and composition of the PLLA-OPOSS hybrids. The samples were dissolved in $\mathrm{CDCl}_{3}$ and ${ }^{1} \mathrm{H}-\mathrm{NMR}$ spectra were obtained with tetramethylsilane (TMS) as the internal reference.

The FTIR measurements were conducted on a FTS 2000 (DIGILAB, America) at room temperature $\left(25^{\circ} \mathrm{C}\right)$. Optical-grade $\mathrm{KBr}$ was grounded in a mortar with a pestle, and enough solid sample ( $1 \mathrm{wt} \%)$ was grounded into $\mathrm{KBr}$ to make $\mathrm{KBr}$ pellets. After the pellets were loaded, a minimum of 16 scans was collected for each sample at a resolution of $\pm 4 \mathrm{~cm}^{-1}$. The X-ray diffraction analysis was obtained with XRD-6000 (Shimadzu Co., Japan) (Ni-filtered Cu $\mathrm{K}_{\alpha}$ radiation, $40 \mathrm{kV}$ and $200 \mathrm{~mA}$ ) over the $2 \theta$ range of $5-40^{\circ}$ at a scanning rate of $4.0^{\circ} / \mathrm{min}$.

A thermal gravimetric analyzer (Pyris Diamond Perkin Elmer, America) was used to investigate the thermooxidative stability of the PLLA/PLLAOPOSS nanocomposites. The samples were heated from room temperature to $600^{\circ} \mathrm{C}$ at a heating rate of $10^{\circ} \mathrm{C} / \mathrm{min}$ under air atmosphere.

The thermal properties of the PLLA/PLLA-OPOSS nanocomposites were characterized by DSC (DSC 204F1, NETZSCH, Germany). The samples were heated to $220^{\circ} \mathrm{C}$ at a heating rate of $10^{\circ} \mathrm{C} / \mathrm{min}$ (first run) under nitrogen, held for $3 \mathrm{~min}$, cooled to room temperature at $40^{\circ} \mathrm{C} / \mathrm{min}$, and then heated to $220^{\circ} \mathrm{C}$ again at $10^{\circ} \mathrm{C} / \mathrm{min}$ (second run). The glass transition temperature, cold crystallization peak temperature, and melting temperature of neat PLLA and PLLA/ PLLA-OPOSS nanocomposites were obtained from the second heating run.

The testing of crystallization rate was investigated by the optical polarimetry (GLY-III) made by Donghua University at Shanghai in China. The samples were melted to press into films between two glass slides at $200^{\circ} \mathrm{C}$, subsequently put into a crystallization room, and then the curves of crystallization rate were recorded when the temperature of the crystallization room was constant.

Polarized optical microscopy images of the melt blended samples were obtained by using an XPR500C (Shanghai Caikang Optical Instrument Co. Ltd., China) polarizing microscope equipped with a video camera and a heat stage. The samples were prepared by melting the blended composites on a hot plate at $200^{\circ} \mathrm{C}$ for 3 minutes, pressing them between two cover slips, and then rapidly cooling them to $125^{\circ} \mathrm{C}$.

\section{Results and discussion \\ 3.1. Formation of PLLA-OPOSS hybrids}

The FTIR spectra of the octaglycidylether POSS, PLLA-OPOSS $\mathrm{S}_{0.50}$ hybrids, and the neat PLLA polymer are shown in Figure 2. In the spectrum of octaglycidylether POSS, the stretching vibration bands at 1088 and $906 \mathrm{~cm}^{-1}$ are assigned to the $\mathrm{Si}-\mathrm{O}-\mathrm{Si}$ moiety and epoxide groups, respectively. In the spectrum of the neat PLLA, the carbonyl band appears around $1760 \mathrm{~cm}^{-1}$ and the hydroxyl stretching vibration band around $3434 \mathrm{~cm}^{-1}$. Under the same condition, it is seen that the band of epoxide groups at $915 \mathrm{~cm}^{-1}$ nearly disappears in the spectrum of PLLA-OPOSS, indicating that the reaction between PLLA and OPOSS has successfully happened. Meanwhile, it is interesting to find that the stretching vibration band of hydroxyl shifts to the higher frequency (viz. $3512 \mathrm{~cm}^{-1}$ ) as compared with that of PLLA (at $3434 \mathrm{~cm}^{-1}$ ) with the reaction occurring. The results indicate that the reaction

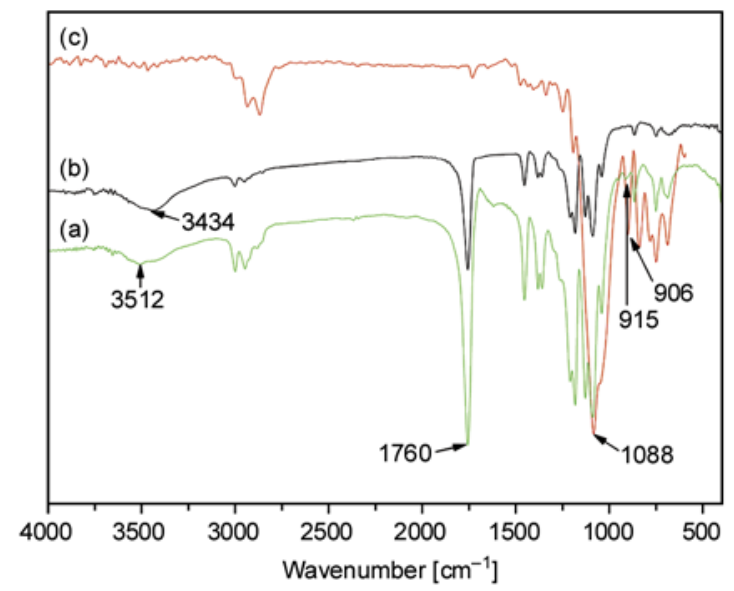

Figure 2. FTIR spectrum of (a) PLLA-OPOSS, (b) PLLA and (c) OPOSS 
occurs between PLLA and OPOSS, which results in the formation of secondary alcohol hydroxyls.

In order to further examine the structure and composition of PLLA-OPOSS hybrids, nuclear magnetic resonance spectroscopy $\left({ }^{1} \mathrm{H}-\mathrm{NMR}\right)$ measurement was performed on OPOSS and PLLA-OPOSS hybrids. The ${ }^{1} \mathrm{H}-\mathrm{NMR}$ spectra of OPOSS and PLLAOPOSS hybrids together with the assignment of the spectra are shown in Figure 3. OPOSS (chloroformd, ppm): $0.64\left(2.01 \mathrm{H}, \mathrm{SiCH}_{2} \mathrm{CH}_{2} \mathrm{CH}_{2} \mathrm{O}\right), 2.61$ and $2.79\left(2.03 \mathrm{H}, \mathrm{OCH}_{2} \mathrm{CH}\right.$ epoxide $), 3.15(1.00 \mathrm{H}$, $\mathrm{OCH}_{2} \mathbf{C H}$ epoxide), $3.34-3.73 \quad(4.3 \mathrm{H}$, $\mathrm{SiCH}_{2} \mathrm{CH}_{2} \mathbf{C H}_{2} \mathrm{O}$ and $\left.\mathrm{SiCH}_{2} \mathrm{CH}_{2} \mathrm{CH}_{2} \mathrm{OCH}_{2}\right)$. PLLA-OPOSS (chloroform-d, ppm): $0.64(3.5 \mathrm{H}$, $\left.\mathrm{SiCH}_{2} \mathrm{CH}_{2} \mathrm{CH}_{2}-\mathrm{O}\right), 1.49$ (3.5H, $\mathrm{SiCH}_{2} \mathbf{C H}_{2} \mathrm{CH}_{2} \mathrm{O}$ ), $1.50-1.60(75 \mathrm{H}$, methyl on PLLA), $2.09(0.75 \mathrm{H}$, $\mathrm{OH}), 2.61$ and $2.80\left(2.00 \mathrm{H}, \mathrm{OCH}_{2} \mathrm{CH}\right.$ epoxide $)$, $3.15\left(1.00 \mathrm{H}, \mathrm{OCH}_{2} \mathbf{C H}\right.$ epoxide), $3.36-3.75(8.5 \mathrm{H}$, $\left.\mathrm{SiCH}_{2} \mathrm{CH}_{2} \mathbf{C H}_{2} \mathrm{O}, \mathrm{SiCH}_{2} \mathrm{CH}_{2} \mathrm{CH}_{2} \mathrm{OCH}_{2}\right), 4.34-$ $4.38\left(1.00 \mathrm{H}, \quad \mathrm{OCH}_{2} \mathrm{CH}\left(\mathrm{CH}_{2}\right) \mathrm{OH}\right), \quad 5.15-5.20$ $(25 \mathrm{H}$, methylidyne on PLLA). The resonance signals which appeared in $0.64,2.61,2.80$ and 3.36$3.75 \mathrm{ppm}$ are assignable to the protons of glycidylether groups of the OPOSS cages; the resonance signals in $1.50-1.60$ and $5.15-5.20 \mathrm{ppm}$ are assignable to the protons of methyl and methylidyne in PLLA, respectively. The integration intensity ratio of the peak for methyl to that for methylidyne in PLLA is 3:1, which corresponds with the structure of PLLA. Moreover, we can note the presence of a characteristic signal of a methylidyne proton in 4.34-4.38 ppm (signal g in Figure 3), which could be ascribed to the reaction product of epoxy of OPOSS and carboxyl of PLLA. Therefore, OPOSS is tethered with PLLA successfully. However, there is some residual methylidyne of OPOSS, which appears at $3.15 \mathrm{ppm}$ (signal e in Figure $3 \mathrm{~b}$ ). In addition, the ratio of integration intensity of peak at
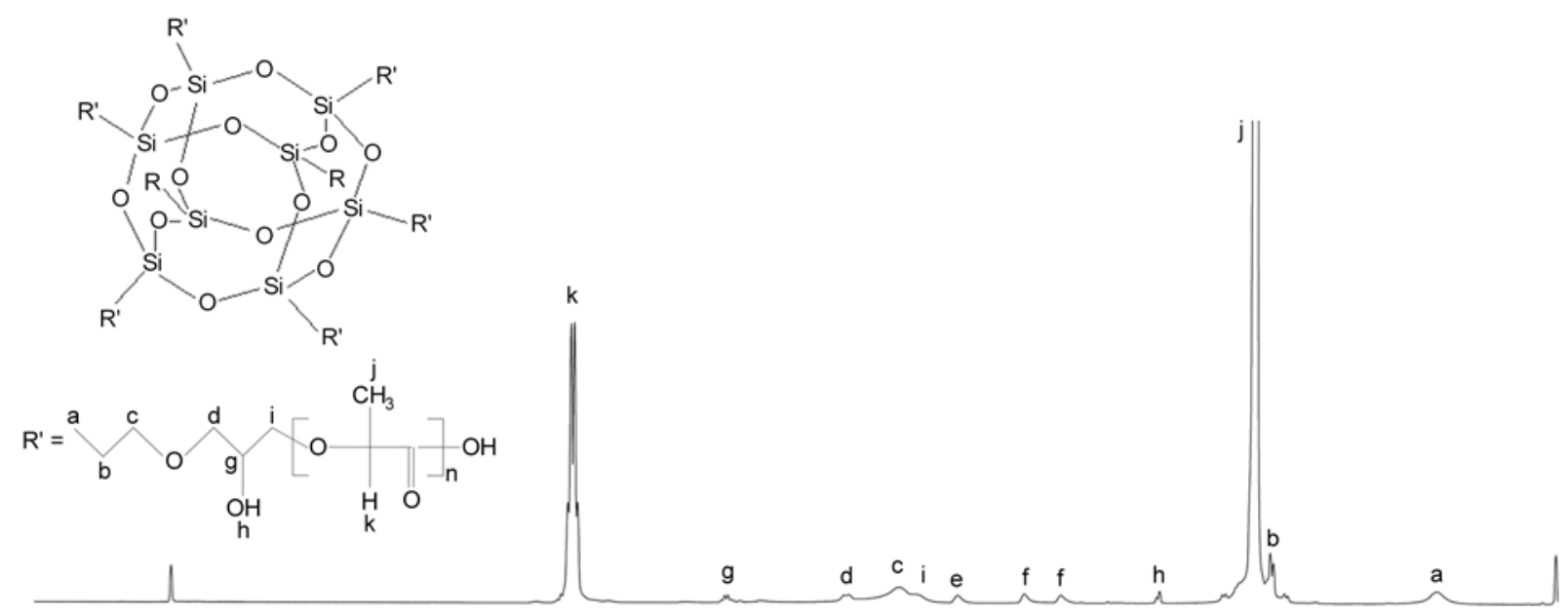

b)

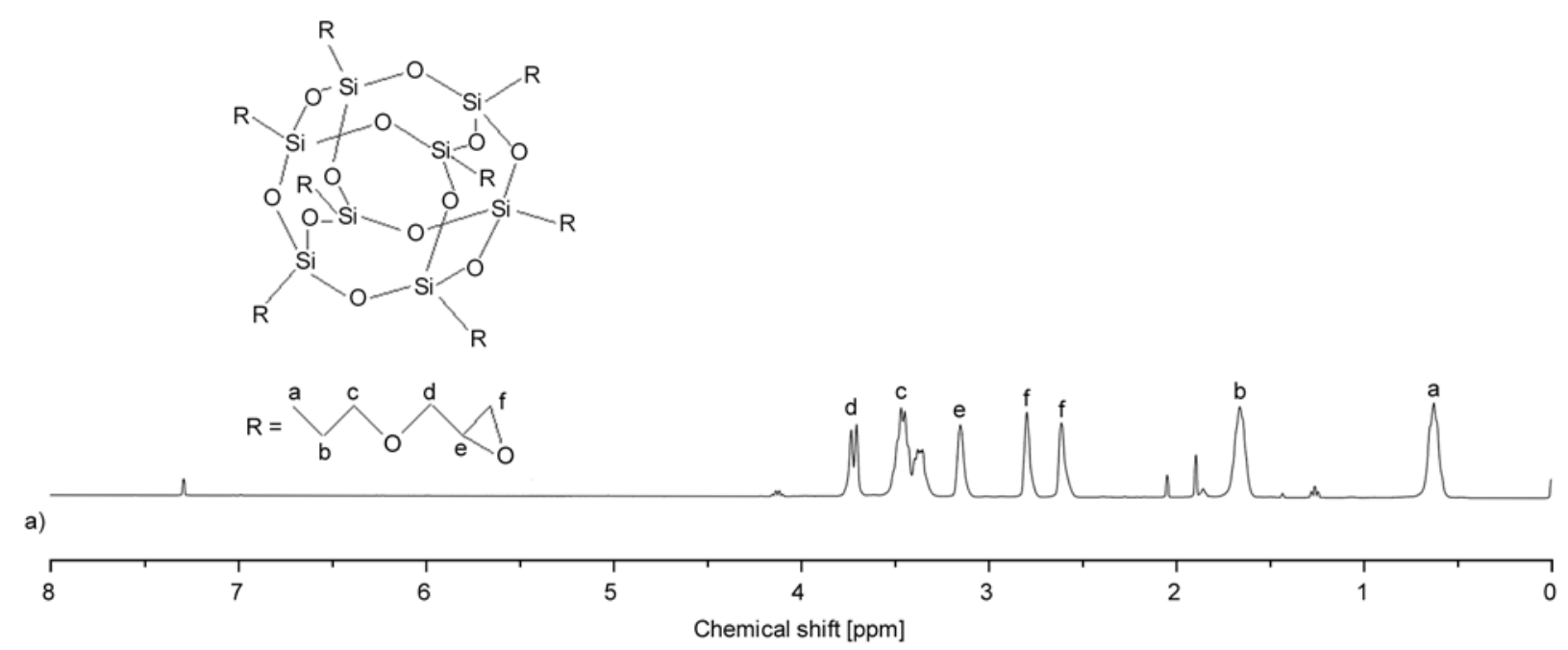

Figure 3. ${ }^{1} \mathrm{H}-\mathrm{NMR}$ spectra of (a) OPOSS, (b) PLLA-OPOSS ${ }_{0.50}$ hybrid 
$0.64 \mathrm{ppm}$ to those of peaks in $4.34-4.38 \mathrm{ppm}$ is 3.5 , which is higher than 2 . Therefore, not all octaglycidylether groups participate in the reaction with PLLA.

The molecular weight of the PLLA-OPOSS hybrid is determined using ${ }^{1} \mathrm{H}-\mathrm{NMR}$ and calculated by the Equation (1):

$M_{\mathrm{n} \text { PLLA }- \text { OPOSS }}=M_{\mathrm{n}_{\mathrm{OPOSS}}}+72 \cdot \frac{k}{\frac{a}{16}}$

where $k$ and $a$ represent the area of the ${ }^{1} \mathrm{H}-\mathrm{NMR}$ signal of PLLA methine hydrogen in 5.15-5.20 ppm and that of OPOSS methylene hydrogen at $0.64 \mathrm{ppm}$, respectively. The value of 72 is the molecular mass of the repeating units of PLLA [38]. The molecular weight of the PLLA-OPOSS $S_{0.50}$ calculated by ${ }^{1} \mathrm{H}-\mathrm{NMR}$ is $9178 \mathrm{~g} / \mathrm{mol}$.

Figure 4 shows the X-ray diffraction patterns of neat PLLA and PLLA-OPOSS hybrids. All spectra of the PLLA-OPOSS hybrids reveal diffraction peaks at $14.8,16.8,19.1$, and $22.4^{\circ}$, which are consistent with the peaks of neat PLLA polymer reported by $\mathrm{Xu}$ et al. [39]. This observation indicates that there is little change in the crystalline structure for the PLLA-OPOSS. Hence, the presence of OPOSS does not alter the packing structure of PLLA chain in the crystals. Moreover, the intensity of the diffraction peaks of PLLA-OPOSS hybrids become stronger than those of neat PLLA, which indicates that the existence of OPOSS may enhance the crystallinity of PLLA. However, the intensity of the diffraction peaks of PLLA decreases with increasing the content of OPOSS, which may be caused by the

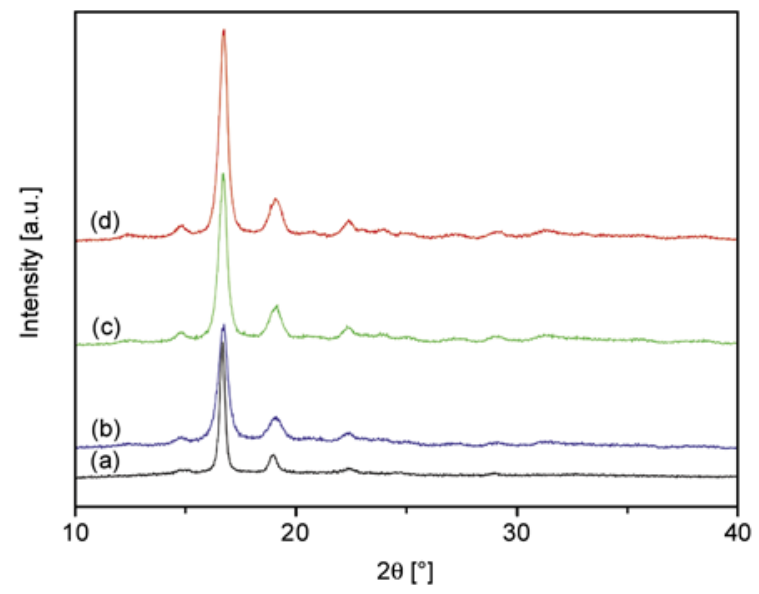

Figure 4. The X-ray diffraction patterns for: (a) neat PLLA and PLLA-OPOSS hybrids of various concentrations (b) $0.50 \mathrm{~mol} \%$, (c) $0.10 \mathrm{~mol} \%$, (d) $0.02 \mathrm{~mol} \%$ cage structure of OPOSS which hinders the crystallization.

\subsection{Thermal properties of PLLA/PLLAĪOPOSS nanocomposites}

A series of PLLA/PLLA-OPOSS nanocomposites were prepared by solution blending of neat PLLA polymer with $1-30 \mathrm{wt} \%$ PLLA-OPOSS $_{0.50}$ hybrids. The TGA curves of the neat PLLA and PLLA/PLLAOPOSS nanocomposites in air atmosphere are displayed in Figure 5. The thermooxidative decomposition temperatures for 5 and $50 \%$ weight loss $\left(T_{0.05}\right.$ and $T_{0.50}$ ) are evaluated from the TGA curves, as listed in Table 1. All the samples display similar degradation profiles within the experimental temperature range, indicating that the presence of OPOSS does not significantly alter the degradation mechanism of PLLA matrix. $T_{0.05}$ and $T_{0.50}$ of neat PLLA are about 286 and $346^{\circ} \mathrm{C}$, respectively. It is seen that $T_{0.05}$ and $T_{0.50}$ of the PLLA/PLLA-OPOSS nanocomposites with PLLA-OPOSS content of 1$20 \mathrm{wt} \%$ are higher than those of neat PLLA and tend to increase with increasing the content of PLLAOPOSS hybrids. This improvement in the thermooxidative stability could be ascribed to the welldispersed POSS cubes in nanocomposites and the

Table 1. Thermooxidative degradation temperatures of PLLA/PLLA-OPOSS nanocomposites under air

\begin{tabular}{|c|c|c|}
\hline \multirow{2}{*}{ Sample code } & \multicolumn{2}{|c|}{ Air condition } \\
\hline & $\mathbf{T}_{0.05}\left[{ }^{\circ} \mathbf{C}\right]$ & $\mathbf{T}_{0.50}\left[{ }^{\circ} \mathbf{C}\right]$ \\
\hline Neat PLLA & 286 & 346 \\
\hline PLLA/PLLA-OPOSS $^{1}$ & 291 & 352 \\
\hline PLLA/PLLA-OPOSS ${ }^{5}$ & 299 & 354 \\
\hline PLLA/PLLA-OPOSS ${ }^{10}$ & 305 & 354 \\
\hline PLLA/PLLA-OPOSS ${ }^{20}$ & 306 & 356 \\
\hline PLLA/PLLA-OPOSS ${ }^{30}$ & 283 & 338 \\
\hline
\end{tabular}

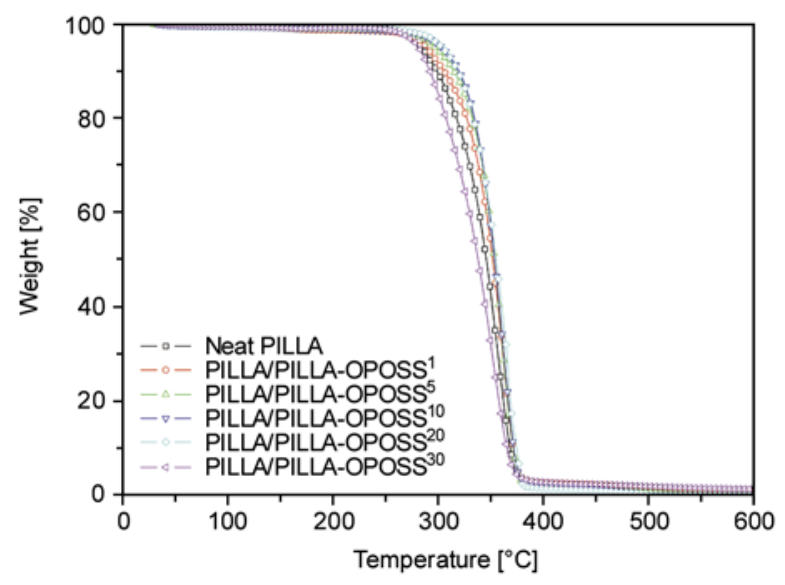

Figure 5. TGA curves of the neat PLLA and PLLA/PLLAOPOSS nanocomposites test under air 
formation barrier of silica layer during the decomposition, which prevents PLLA from further degradation.

However, $T_{0.05}$ and $T_{0.50}$ of PLLA/PLLA-OPOSS ${ }_{0.5}{ }^{30}$ are slightly lower than those of neat PLLA. It is due to the fact that PLLA-OPOSS with low molecular weight compared to the neat PLLA matrix results in low thermooxidative stability of the nanocomposites. In this situation, the lower molecular weight effect of PLLA-OPOSS became dominant over the reinforcing effect of the OPOSS molecules for the nanocomposites with high PLLA-OPOSS content of $30 \mathrm{wt} \%$.

Figure 6 displays the DSC thermograms of the neat PLLA polymer and PLLA/PLLA-OPOSS nanocomposites with various PLLA-OPOSS $\mathrm{S}_{0.50}$ hybrid content of $1-30 \mathrm{wt} \%$. The cold-crystallization temperatures of PLLA/PLLA-OPOSS nanocomposites shifts to higher temperatures compared to the neat PLLA. Moreover, the crystallization exothermic peak area becomes higher than that of the neat PLLA. This suggested that the crystallization rates of the nanocomposites is higher than the neat PLLA because of the heterogeneous nucleation effect of the OPOSS molecules dispersed uniformly in the PLLA matrix. On

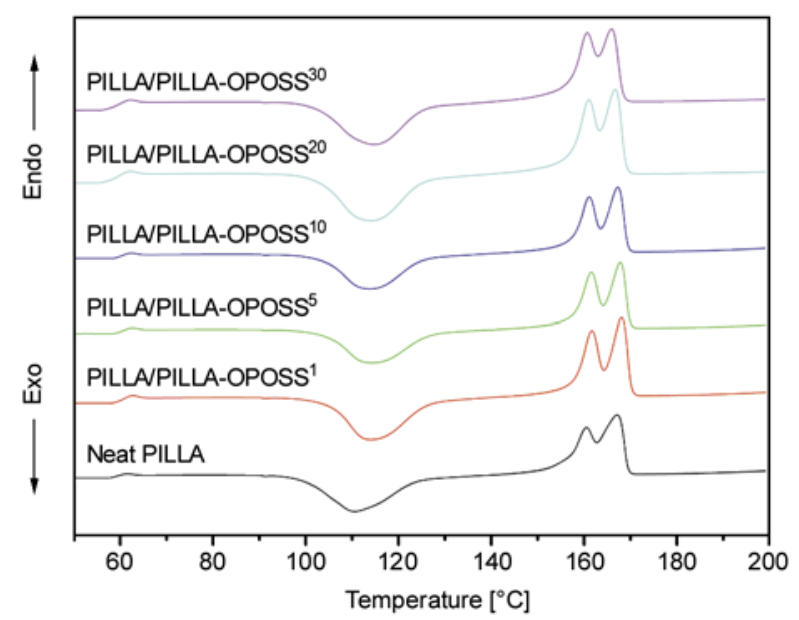

Figure 6. The DSC thermographs(second run)of neat PLLA homopolymer and PLLA/PLLA-OPOSS nanocomposites the other side, the glass transition temperature of the PLLA/PLLA-OPOSS nanocomposites remains consistent with the neat PLLA, regardless of the PLLA-OPOSS content, as summarized in Table 2. In addition, for all of the neat PLLA and PLLA/ PLLA-OPOSS nanocomposites appear two melting peaks, as shown in Figure 6. The low-temperature melting peak results from melting of defective crystalline grains and the high-temperature melting peak due to melting of crystalline grains with relatively perfect structure. The melting temperature $\left(T_{\mathrm{m}}\right)$ of the PLLA/PLLA-OPOSS nanocomposites decreases with increasing PLLA-OPOSS hybrid content because of plasticity of the lower molecular weight of the PLLA-OPOSS hybrid in the PLLA matrix. In addition, the melting temperature of the PLLA/PLLA-OPOSS nanocomposites with PLLAOPOSS hybrid content of $1-10 \mathrm{wt} \%$ is higher than that of the neat PLLA due to the cage structure of OPOSS, whereas the low molecular weight of PLLA-OPOSS effect becomes dominant when PLLA-OPOSS hybrid content arrives at the range of $20-30 \mathrm{wt} \%$.

\subsection{Dynamic isothermal crystallization}

In order to understand the effect of the addition of PLLA-OPOSS hybrids on the crystallization rate of PLLA, isothermal crystallization behavior of PLLA/ PLLA-OPOSS nanocomposites were investigated by the optical polarimetry (GLY-III) tester. The transmitted light intensity increases with the increasing of crystallinity and finally levels off when crystallization completes. As an index of crystallinity, $\left(I_{\mathrm{t}}-I_{0}\right) /\left(I_{\infty}-I_{0}\right)$ is used to define the relative light intensity, where $I_{\mathrm{t}}$ and $I_{0}$ are the $I$ value at time $t_{\mathrm{c}}=t$ and 0 , respectively, $I_{\infty}$ is the $I$ value when it levels off. Figure 7 shows the typical $\left(I_{\mathrm{t}}-I_{0}\right) /\left(I_{\infty}-I_{0}\right)$ changes with $t_{\mathrm{c}}$ for PLLA/PLLAOPOSS $^{30}$ films, where the starting, half, and ending times for overall PLLA/PLLA-OPOSS ${ }^{30}$ crystallization $\left[t_{\mathrm{c}}(\mathrm{S}), t_{\mathrm{c}}(1 / 2)\right.$, and $t_{\mathrm{c}}(\mathrm{E})$, respectively] are

Table 2. Thermal transition properties (second run) of neat PLLA and PLLA/PLLA-OPOSS nanocomposites

\begin{tabular}{|c|c|c|c|c|c|c|}
\hline \multirow{2}{*}{ Sample code } & \multirow{2}{*}{$\begin{array}{c}\mathbf{T}_{\mathbf{g}} \\
{\left[{ }^{\circ} \mathbf{C}\right]}\end{array}$} & \multirow{2}{*}{$\begin{array}{c}\mathbf{T}_{\mathbf{c c}} \\
{\left[{ }^{\circ} \mathbf{C}\right]}\end{array}$} & \multirow{2}{*}{$\begin{array}{l}\Delta \mathbf{H}_{\mathbf{c c}} \\
{[\mathbf{J} / \mathrm{g}]}\end{array}$} & \multicolumn{2}{|c|}{$\mathbf{T}_{\mathrm{m}}\left[{ }^{\circ} \mathbf{C}\right]$} & \multirow{2}{*}{$\begin{array}{l}\Delta \mathbf{H}_{\mathrm{m}} \\
|\mathbf{J} / \mathbf{g}|\end{array}$} \\
\hline & & & & $\mathbf{T}_{\mathrm{m} 1}$ & $T_{\mathrm{m} 2}$ & \\
\hline Neat PLLA & 59.8 & 110.5 & 38.1 & 160.5 & 167.2 & 42.9 \\
\hline PLLA/PLLA-OPOSS $^{1}$ & 60.7 & 114.0 & 40.0 & 161.7 & 168.2 & 42.1 \\
\hline PLLA/PLLA-OPOSS ${ }^{5}$ & 60.7 & 114.0 & 39.5 & 161.6 & 167.8 & 40.4 \\
\hline PLLA/PLLA-OPOSS $^{10}$ & 60.7 & 113.7 & 38.1 & 161.0 & 167.3 & 41.2 \\
\hline PLLA/PLLA-OPOSS ${ }^{20}$ & 59.5 & 114.1 & 38.8 & 161.0 & 166.7 & 42.5 \\
\hline PLLA/PLLA-OPOSS ${ }^{30}$ & 59.6 & 114.8 & 39.3 & 160.7 & 165.9 & 40.7 \\
\hline
\end{tabular}




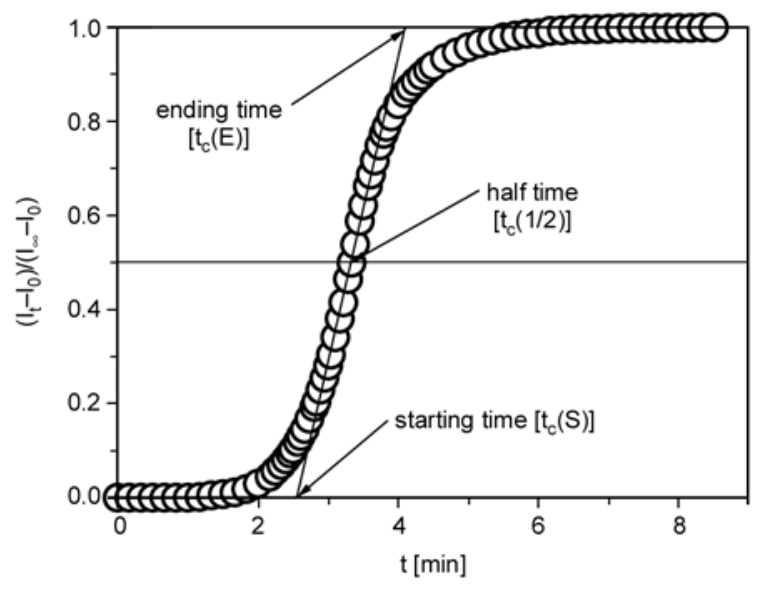

Figure 7. Typical $\left(I_{\mathrm{t}}-I_{0}\right) /\left(I_{\infty}-I_{0}\right)$ change with for PLLA/ PLLA-OPOSS ${ }^{30}$ film at $110^{\circ} \mathrm{C}$

defined. Figure 8 plotted the evaluated $t_{\mathrm{c}}(\mathrm{S}), t_{\mathrm{c}}(1 / 2)$, and $t_{\mathrm{c}}(\mathrm{E})$ as a function of $T_{\mathrm{c}}$. As shown in Figure 8, the $t_{\mathrm{c}}(\mathrm{S}), t_{\mathrm{c}}(1 / 2)$, and $t_{\mathrm{c}}(\mathrm{E})$ of PLLA/PLLA-OPOSS nanocomposites with $1-30 \mathrm{wt} \%$ of PLLA-OPOSS $\mathrm{S}_{0.5}$ were shorter than or close to those of neat PLLA film. The short $t_{\mathrm{c}}(\mathrm{S}), t_{\mathrm{c}}(1 / 2)$, and $t_{\mathrm{c}}(\mathrm{E})$ as observed are caused by PLLA-OPOSS which acts as a heterogeneous nucleation agent for the crystallization of PLLA. Compared with the crystallization temperature at $100,110,120,130^{\circ} \mathrm{C}$ (Figure 7), the values of $t_{\mathrm{c}}(\mathrm{S}), t_{\mathrm{c}}(1 / 2)$, and $t_{\mathrm{c}}(\mathrm{E})$ for four specimen, had the lowest values at $120^{\circ} \mathrm{C}$, except for those for PLLA/PLLA-OPOSS ${ }^{1}$. The results indicate that PLLA-OPOSS hybrids accelerate crystallization of PLLA as a heterogeneous nucleation agent with a lower content of PLLA-OPOSS hybrids, However, PLLA-OPOSS hybrids with a higher content hinder segmental motion to restrain crystallization of PLLA.

Isothermal crystallization kinetics traced by light intensity are analyzed with the Avrami theory [40], which is expressed in the Equation (2):

$1-\frac{I_{\mathrm{t}}-I_{0}}{I_{\infty}-I_{0}}=\exp \left(-k t_{\mathrm{c}}^{\mathrm{n}}\right)$

where $\left(I_{\mathrm{t}}-I_{0}\right) /\left(I_{\infty}-I_{0}\right)$ is the percentage of relative crystallization, $k$ the crystallization rate constant, and $n$ the Avrami exponent constant depending on the nucleation and growth mechanism. Equation (2) can be transformed to Equation (3).

$\ln \left[-\ln \left(1-\frac{I_{\mathrm{t}}-I_{0}}{I_{\infty}-I_{0}}\right)\right]=\ln k+n \ln t_{\mathrm{c}}$
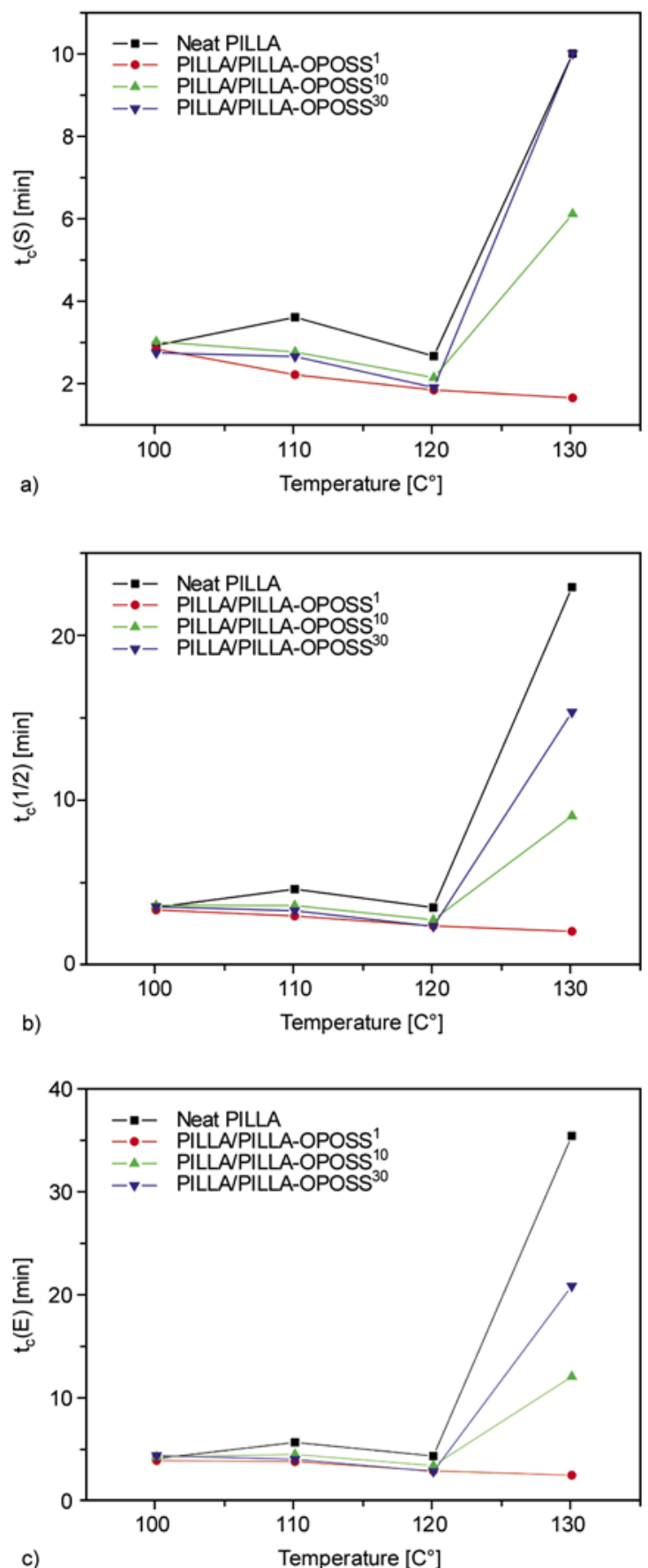

Figure 8. Starting, half, and ending times for neat PLLA and PLLA/PLLA-OPOSS nanocomposites [a) $t_{\mathrm{c}}(\mathrm{S})$, b) $t_{\mathrm{c}}(1 / 2)$, and c) $\left.t_{\mathrm{c}}(\mathrm{E})\right]$

The effects of PLLA-OPOSS content on the plot of $\ln \left\{-\ln \left[1-\left(I_{\mathrm{t}}-I_{0}\right) /\left(I_{\infty}-I_{0}\right)\right]\right\}$ versus $\ln t_{\mathrm{c}}$ could be seen in Figure 8 . The overall crystallization rate may be due to the change either in the crystal growth rate or in the nucleation rate. As shown in Figure 9, the curves have a good linear relationship at the beginning, and then exhibit the nonlinear relationship at the end, which may be ascribed to the sec- 

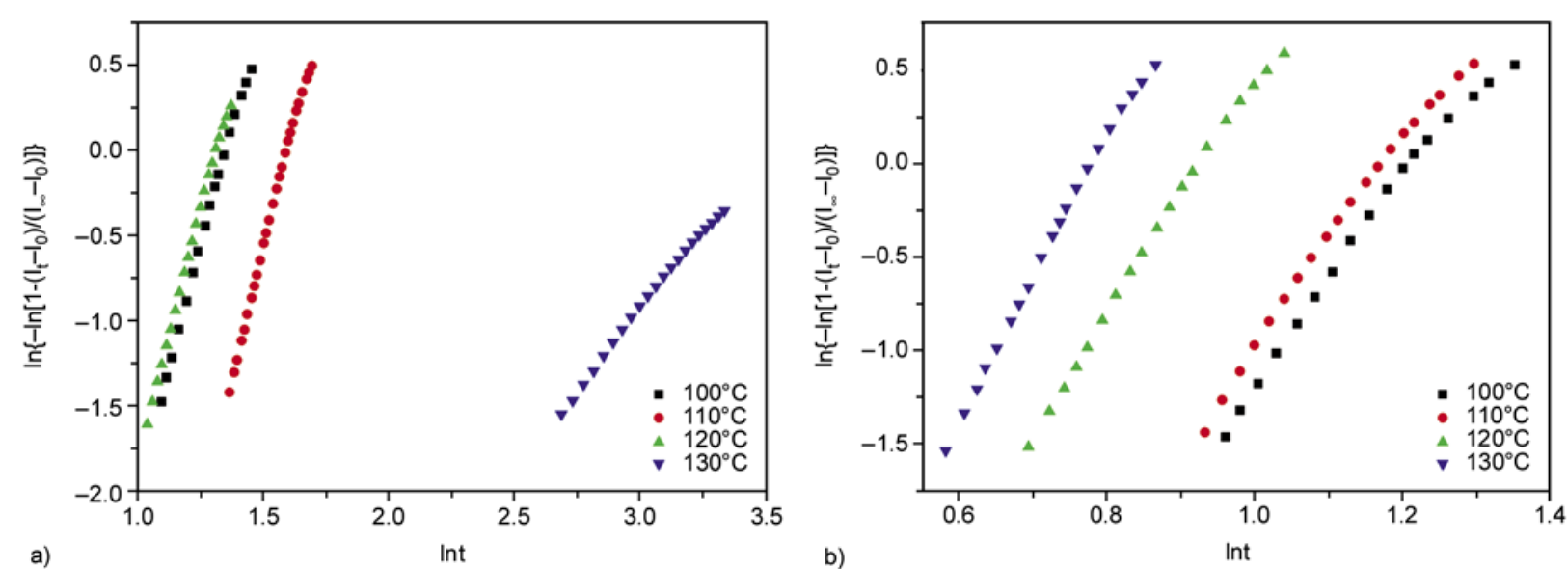

a) Int
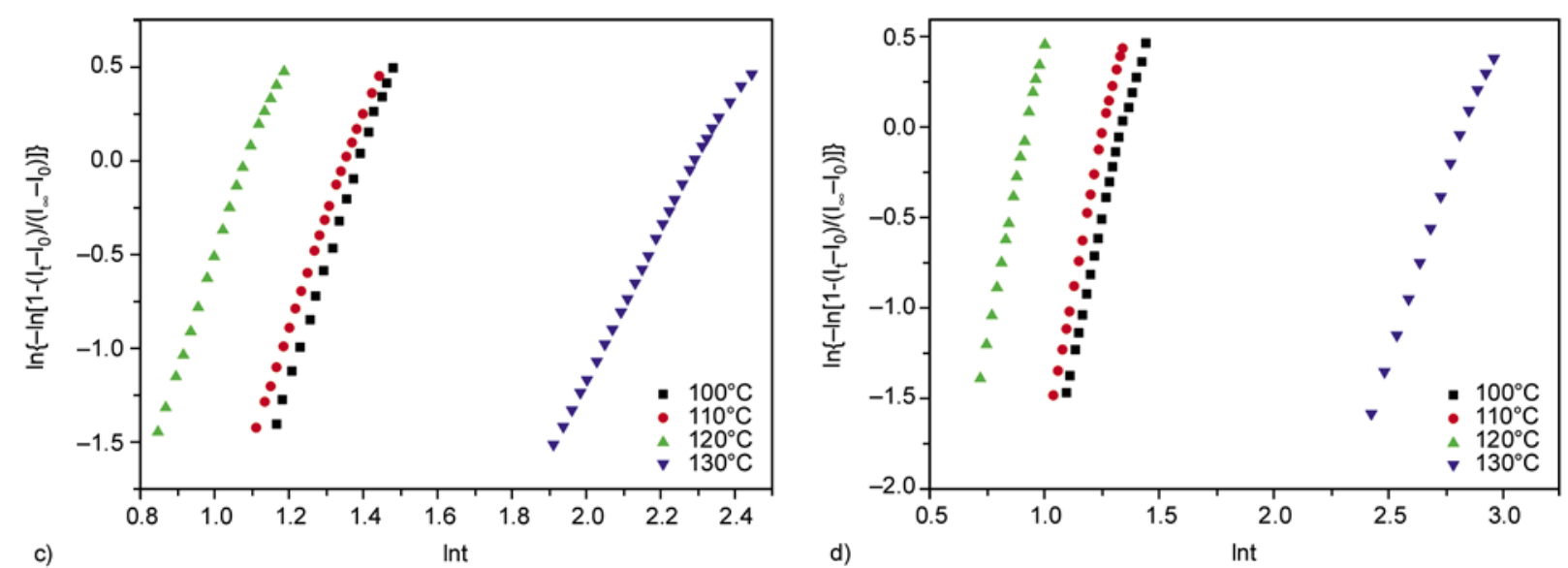

Figure 9. Plots of the degree of crystallinity $\ln \left\{-\ln \left[1-\left(I_{\mathrm{t}}-I_{0}\right) /\left(I_{\infty}-I_{0}\right)\right]\right\}$ versus the crystallization time $\ln t_{\mathrm{c}}$ for isothermal crystallization (a) Pure PLLA, (b) PLLA/PLLA-OPOSS 1.0, (c) PLLA/PLLA-OPOSS 10, (d) PLLA/PLLAOPOSS 30

ondary crystallization. The basically parallel curves are shown in the process of isothermal crystallization at different temperatures, their crystallographic action is similar.

According to Equation (3), when plotting $\ln \left\{-\ln \left[1-\left(I_{\mathrm{t}}-I_{0}\right) /\left(I_{\infty}-I_{0}\right)\right]\right\}$ against $\ln t_{\mathrm{c}}$ (Figure 8), the $n$ and $k$ values could be directly obtained from the slope and the natural logarithmic value of the intercept, respectively. From Table 3, it is found that with increasing crystallization temperature the exponent $n$ first increases and then decreases for most of samples. Moreover, it can be observed that the exponent $n$ is found to range from 3.8 to 6.7, which is simlar to those for PLA/nucleating agent systems reported by Liao et al. [41] in most cases. It implies that the crystals in the PLLA/PLLAOPOSS nanocomposites showed heterogeneous nucleation and spherulitic growth [42]. The values of $n$ reported in literatures are related with many ingredients, such as the secondary crystallization,
Table 3. Values of Avrami parameter at various isothermal crystallization temperatures

\begin{tabular}{|c|c|c|c|}
\hline Samples & $\begin{array}{c}\mathbf{T}_{\mathbf{c}} \\
{\left[{ }^{\circ} \mathbf{C}\right]}\end{array}$ & $\mathrm{n}$ & $\begin{array}{c}-\operatorname{lnk} k \\
{\left[\min ^{-n}\right]}\end{array}$ \\
\hline \multirow{4}{*}{ Neat PLLA } & 100 & 5.53 & 7.50 \\
\hline & 110 & 6.02 & 9.63 \\
\hline & 120 & 5.75 & 7.57 \\
\hline & 130 & 3.87 & 6.53 \\
\hline \multirow{4}{*}{ PLLA/PLLA-OPOSS $^{1}$} & 100 & 5.20 & 6.36 \\
\hline & 110 & 5.39 & 6.36 \\
\hline & 120 & 6.19 & 5.76 \\
\hline & 130 & 6.39 & 5.79 \\
\hline \multirow{4}{*}{ PLLA/PLLA-OPOSS ${ }^{10}$} & 100 & 6.10 & 8.50 \\
\hline & 110 & 5.77 & 7.83 \\
\hline & 120 & 5.81 & 6.34 \\
\hline & 130 & 3.87 & 8.93 \\
\hline \multirow{4}{*}{ PLLA/PLLA-OPOSS ${ }^{30}$} & 100 & 5.67 & 7.64 \\
\hline & 110 & 6.55 & 8.29 \\
\hline & 120 & 6.72 & 6.23 \\
\hline & 130 & 3.79 & 10.75 \\
\hline
\end{tabular}

the density of spherulites, nucleation mode and growth mechanism, etc [43]. 


\subsection{Polarized optical microscopy (POM)}

The nucleating effect of PLLA-OPOSS hybrids on the crystallization of PLLA is also confirmed by POM. Figure 10 shows polarized optical microscopy images of the crystallization of neat PLLA and PLLA/PLLA-OPOSS nanocomposites. The test samples were prepared by melting the samples on a hot plate at $200^{\circ} \mathrm{C}$ for 3 minutes, and cooled to $125^{\circ} \mathrm{C}$,

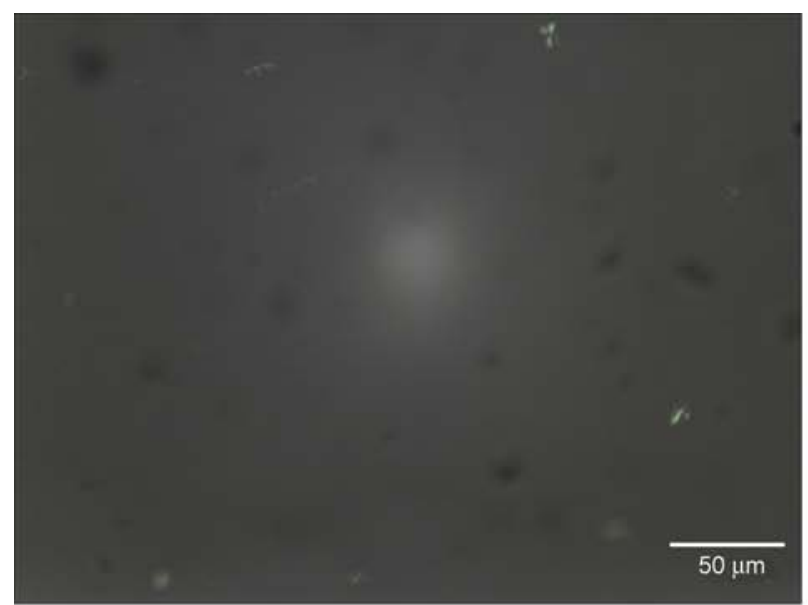

a)

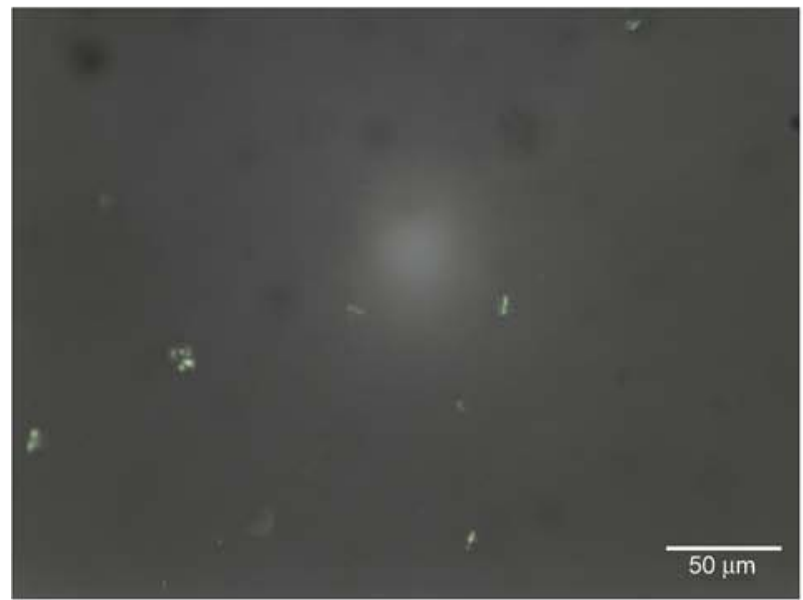

c)

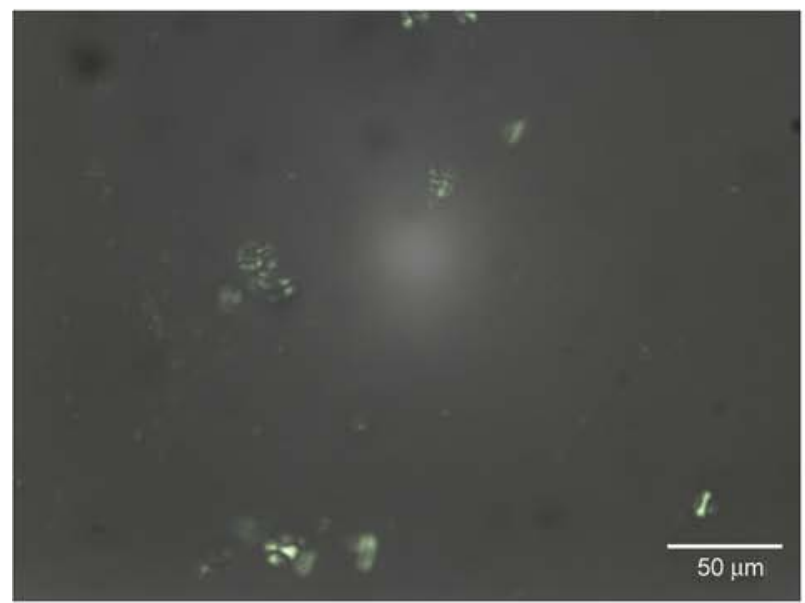

e) then maintained for a different crystallization time. The spherulites of PLLA/PLLA-OPOSS nanocomposites are smaller in size and larger in numbers than those of the neat PLLA. As an approximate inclination, the nucleation density increases with increasing of the content of PLLA-OPOSS hybrids. It indicates that PLLA-OPOSS hybrids act as an effective nucleating agent to initiate nucleation and

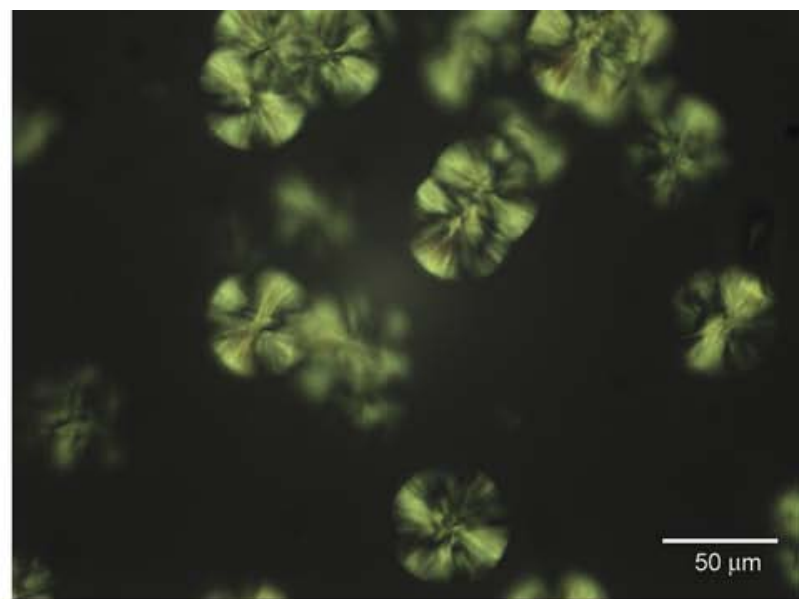

b)

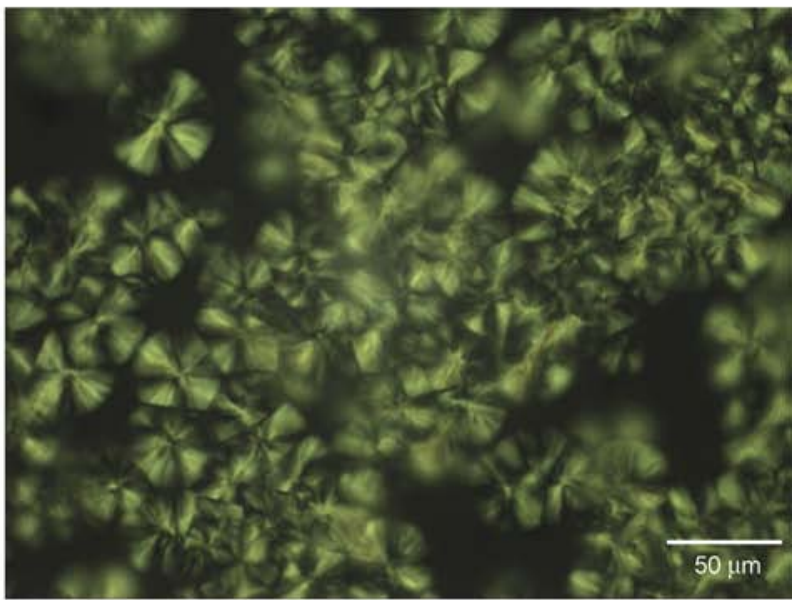

d)

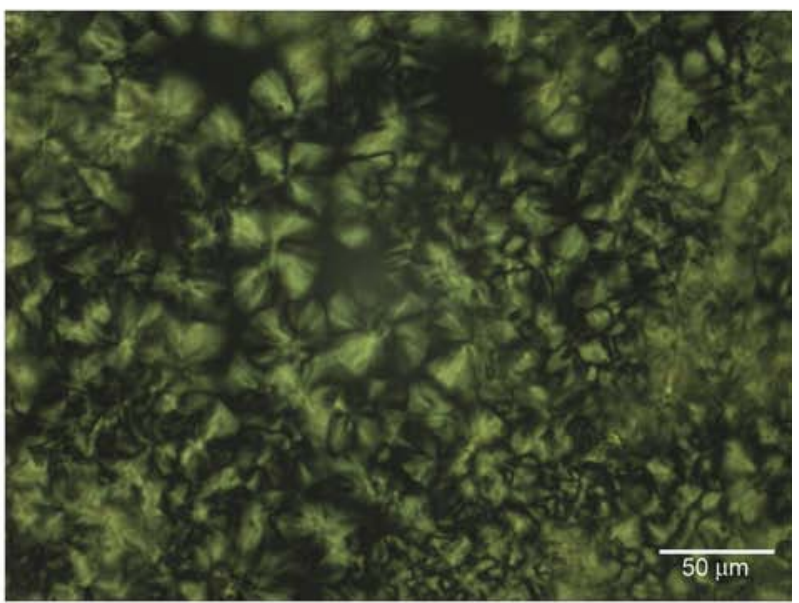

f)

Figure 10. Polarized optical photomicrographs of neat PLLA and PLLA/PLLA-OPOSS nanocomposites at $125^{\circ} \mathrm{C}$. Neat PLLA: a) $40 \mathrm{~s}$, b) $5 \mathrm{~min}$; PLLA/PLLA-OPOSS ${ }^{10}$ : c) $40 \mathrm{~s}$, d) $5 \mathrm{~min}$; PLLA/PLLA-OPOSS ${ }^{30}$ : e) $40 \mathrm{~s}$, f) 5 min 
increase the nucleation density for PLLA crystallization.

\section{Conclusions}

In this work, PLLA-OPOSS hybrids were prepared via solution ring-opening polymerization. The formation of secondary hydroxyls due to the reaction between main PLLA chains and OPOSS is evidenced by FTIR and ${ }^{1} \mathrm{H}-\mathrm{NMR}$. X-ray analysis indicates that the presence of OPOSS does not alter the packing structure of PLLA chain in the crystals. The PLLA-OPOSS hybrid with $0.50 \mathrm{~mol} \%$ OPOSS content is solution-mixed with the neat PLLA polymer to obtain PLLA/PLLA-OPOSS nanocomposites with various PLLA-OPOSS content of $1-30 \mathrm{wt} \%$. It was found that the glass transition temperature of the PLLA/PLLA-OPOSS nanocomposites remained consistent with the neat PLLA and the thermooxidative stability of PLLA/PLLA-OPOSS nanocomposites is improved with the PLLA-OPOSS content of $1-20 \mathrm{wt} \%$ compared to the pristine PLLA polymer. PLLA/PLLA-OPOSS nanocomposites have the highest crystallization rate at $120^{\circ} \mathrm{C}$, except for PLLA/ PLLA-OPOSS ${ }^{1}$. The nucleation density increases with increase in the PLLA-OPOSS content.

\section{Acknowledgements}

The work was financially supported by The Key Technology R\&D Program of Jiangsu (Project No. BE2010176), Natural science fund for colleges and universities in Jiangsu Province (Project No. 08KJB430004), Scientific and Technological Developing Scheme of Zhenjiang City (Project No. SH2008073).

\section{References}

[1] Reed A. M., Gilding D. K.: Biodegradable polymers for use in surgery - Poly(glycolic)/poly(lactic acid) homo and copolymers: 2 . In vitro degradation. Polymer, 22, 494-498 (1981).

DOI: $10.1016 / 0032-3861(81) 90168-3$

[2] Kalb B., Pennings A. J.: General crystallization behaviour of poly(L-lactic acid). Polymer, 21, 607-612 (1980).

DOI: 10.1016/0032-3861(80)90315-8

[3] Marega C., Marigo A., Di Noto V., Zannetti R., Martorana A., Paganetto G.: Structure and crystallization kinetics of poly(L-lactic acid). Die Makromolekulare Chemie, 193, 1599-1606 (1992).

DOI: $10.1002 / \mathrm{macp} .1992 .021930704$
[4] Wu D. F., Wu L., Zhang M., Zhao Y. L.: Viscoelasticity and thermal stability of polylactide composites with various functionalized carbon nanotubes. Polymer Degradation and Stability, 93, 1577-1584 (2008). DOI: $10.1016 /$ j.polymdegradstab.2008.05.001

[5] Ouchi T., Miyazaki H., Arimura H., Tasaka F., Hamada A., Ohya Y.: Synthesis of biodegradable amphiphilic AB-type diblock copolymers of lactide and depsipeptide with pendant reactive groups. Journal of Polymer Science Part A: Polymer Chemistry, 40, 1218-1225 (2002). DOI: $10.1002 /$ pola.10211

[6] Wang L., Ma W., Gross R. A., McCarthy S. P.: Reactive compatibilization of biodegradable blends of poly (lactic acid) and poly( $\varepsilon$-caprolactone). Polymer Degradation and Stability, 59, 161-168 (1998). DOI: 10.1016/S0141-3910(97)00196-1

[7] Sarazin P., Favis B. D.: Morphology control in co-continuous poly(L-lactide)/polystyrene blends: A route towards highly structured and interconnected porosity in poly(L-lactide) materials. Biomacromolecules, 4, 1669-1679 (2003). DOI: $10.1021 / \mathrm{bm} 030034+$

[8] Sarazin P., Roy X., Favis B. D.: Controlled preparation and properties of porous poly(L-lactide) obtained from a co-continuous blend of two biodegradable polymers. Biomaterials, 25, 5965-5978 (2004). DOI: $10.1016 /$ j.biomaterials.2004.01.065

[9] Ray S. S., Yamada K., Okamoto M., Ogami A., Ueda K.: New polylactide/layered silicate nanocomposites. 3. High-performance biodegradable materials. Chemistry of Materials, 15, 1456-1465 (2003).

DOI: $10.1021 / \mathrm{cm} 020953 \mathrm{r}$

[10] Paul M-A., Delcourt C., Alexandre M., Degée P., Monteverde F., Rulmont A., Dubois P.: (Plasticized) polylactide/(organo-)clay nanocomposites by in situ intercalative polymerization. Macromolecular Chemistry and Physics, 206, 484-498 (2005).

DOI: $10.1002 / \mathrm{macp} .200400324$

[11] Chen G-X., Kim H-S., Park B. H., Yoon J-S.: Controlled functionalization of multiwalled carbon nanotubes with various molecular-weight poly(L-lactic acid). The Journal of Physical Chemistry B, 109, $22237-$ 22243 (2005).

DOI: $10.1021 / \mathrm{jp} 054768 \mathrm{n}$

[12] Jiang L., Zhang J. W., Wolccott M. P.: Comparison of polylactide/nano-sized calcium carbonate and polylactide/montmorillonite composites: Reinforcing effects and toughening mechanisms. Polymer, 48, 7632-7644 (2007).

DOI: 10.1016/j.polymer.2007.11.001

[13] Singh S., Ray S. S.: Polylactide based nanostructured biomaterials and their applications. Journal of Nanoscience and Nanotechnology, 7, 2596-2615 (2007). DOI: $10.1166 /$ jnn.2007.909 
[14] Yoon J. T., Jeong Y. G., Lee S. C., Min B. G.: Influences of poly(lactic acid)-grafted carbon nanotube on thermal, mechanical, and electrical properties of poly(lactic acid). Polymers for Advanced Technologies, 20, 631-638 (2009).

DOI: $10.1002 /$ pat.1312

[15] Lichtenhan J. D., Vu N. Q., Carter J. A., Gilman L. W., Feher F. J.: Silsesquioxane-siloxane copolymers from polyhedral silsesquioxanes. Macromolecules, 26, 2141-2142 (1993).

DOI: $10.1021 / \mathrm{ma} 00060 \mathrm{a} 053$

[16] Shockey E., Jones P. F., Chaffee K. P., Lichtenhan J. D.: Thermal behavior of polyhedral oligosilsesquioxane (POSS)/siloxane copolymers. Polymer Preprints, 36, 391-392 (1995).

[17] Kannan R., Salacinski H., Butler P., Seifalian A.: Polyhedral oligomeric silsesquioxane nanocomposites: the next generation material for biomedical applications. Accounts of Chemical Research, 38, 879-884 (2005). DOI: 10.1021/ar050055b

[18] Harrison P.: Silicate cages: Precursors to new materials. Journal of Organometallic Chemistry, 542, 141-183 (1997). DOI: $10.1016 / \mathrm{S} 0022-328 X(96) 06821-0$

[19] Qiu Z. B., Pan H.: Preparation, crystallization and hydrolytic degradation of biodegradable poly(1-lactide)/polyhedral oligomeric silsesquioxanes nanocomposite. Composites Science and Technology, 70, 10891094 (2010).

DOI: 10.1016/j.compscitech.2009.11.001

[20] Liu Y. H., Zeng K., Zheng S. X.: Organic-inorganic hybrid nanocomposites involving novolac resin and polyhedral oligomeric silsesquioxane. Reactive and Functional Polymers, 67, 627-635 (2007).

DOI: $10.1016 /$ j.reactfunctpolym.2007.04.002

[21] Joshi M., Butola B. S., Simon G., Kukaleva N.: Rheological and viscoelastic behavior of HDPE/octamethylPOSS nanocomposites. Macromolecules, 39, 18391849 (2006). DOI: $10.1021 / \mathrm{ma} 051357 \mathrm{w}$

[22] Fina A., Tabuani D., Frache A., Camino G.: Polypropylene-polyhedral oligomeric silsesquioxanes (POSS) nanocomposites. Polymer, 46, 7855-7866 (2005). DOI: $10.1016 /$ j.polymer.2005.06.121

[23] Ni Y., Zheng S., Nie K.: Morphology and thermal properties of inorganic-organic hybrids involving epoxy resin and polyhedral oligomeric silsesquioxanes. Polymer, 45, 5557-5568 (2004). DOI: $10.1016 /$ j.polymer.2004.06.008

[24] Liu Y., Zheng S., Nie K.: Epoxy nanocomposites with octa(propylglycidyl ether) polyhedral oligomeric silsesquioxane. Polymer, 46, 12016-12025 (2005). DOI: 10.1016/j.polymer.2005.09.056

[25] Ni Y., Zheng S. X.: Epoxy resin containing octamaleimidophenyl polyhedral oligomeric silsesquioxane. Macromolecular Chemistry and Physics, 206, 2075-2083 (2005).

DOI: $10.1002 /$ macp. 200500267
[26] Liu H. Z., Zheng S. X., Nie K. M.: Morphology and thermomechanical properties of organic-inorganic hybrid composites involving epoxy resin and an incompletely condensed polyhedral oligomeric silsesquioxane. Macromolecules, 38, 5088-5097 (2005).

DOI: $10.1021 / \mathrm{ma} 0504318$

[27] Zhang W. H., Fu B. X., Seo Y., Schrag E., Hsiao B., Mather P. T., Yang N-L., Xu D., Ade H., Rafailovich M., Sokolov J.: Effect of methyl methacrylate/polyhedral oligomeric silsesquioxane random copolymers in compatibilization of polystyrene and poly(methyl methacrylate) blends. Macromolecules, 35, 8029-8038 (2002).

DOI: $10.1021 / \mathrm{ma} 020725 \mathrm{i}$

[28] Kopesky E. T., Haddad T. S., McKinley G. H., Cohen R. E.: Miscibility and viscoelastic properties of acrylic polyhedral oligomeric silsesquioxane-poly(methyl methacrylate) blends. Polymer, 46, 4743-4752 (2005). DOI: $10.1016 /$ j.polymer.2005.04.001

[29] Kopesky E. T., McKinley G. H., Cohen R. E.: Toughened poly(methyl methacrylate) nanocomposites by incorporating polyhedral oligomeric silsesquioxanes. Polymer, 47, 299-309 (2006). DOI: $10.1016 /$ j.polymer.2005.10.143

[30] Huang C-F., Kuo S-W., Lin F-L., Huang W-J., Wang C-F., Chen W-Y., Chang F-C.: Influence of PMMAchain-end tethered polyhedral oligomeric silsesquioxanes on the miscibility and specific interaction with phenolic blends. Macromolecules, 39, 300-308 (2006). DOI: $10.1021 / \mathrm{ma} 051923 \mathrm{n}$

[31] Liu H., Zheng S.: Polyurethane networks nanoreinforced by polyhedral oligomeric silsesquioxane. Macromolecular Rapid Communications, 26, 196-200 (2005). DOI: $10.1002 /$ marc.200400465

[32] Turri S., Levi M.: Structure, dynamic properties, and surface behavior of nanostructured ionomeric polyurethanes from reactive polyhedral oligomeric silsesquioxanes. Macromolecules, 38, 5569-5574 (2005). DOI: $10.1021 / \mathrm{ma} 047304 \mathrm{~g}$

[33] Yoon K. H., Polk M. B., Park J. H., Min B. G., Schiraldi D. A.: Properties of poly(ethylene terephthalate) containing epoxy-functionalized polyhedral oligomeric silsesquioxane. Polymer International, 54, 47-53 (2005). DOI: $10.1002 /$ pi.1661

[34] Zeng J., Kumar S., Iyer S., Schiraldi D. A., Gonzalez R. I.: Reinforcement of poly(ethylene terephthalate) fibers with polyhedral oligomeric silsesquioxanes (POSS). High Performance Polymers, 17, 403-424 (2005).

DOI: $10.1177 / 0954008305055562$

[35] Kim J. K., Yoon K. H., Bang D. S., Park Y-B., Kim HU., Bang Y-H.: Morphology and rheological behaviors of poly(ethylene terephthalate) nanocomposites containing polyhedral oligomeric silsesquioxanes. Journal of Applied Polymer Science, 107, 272-279 (2008). DOI: $10.1002 /$ app. 27038 
[36] Zhao Y., Schiraldi D. A.: Thermal and mechanical properties of polyhedral oligomeric silsesquioxane (POSS)/polycarbonate composites. Polymer, 46, 11640-11647 (2005).

DOI: $10.1016 /$ j.polymer.2005.09.070

[37] Lee J. H., Jeong Y. G.: Preparation and characterization of nanocomposites based on polylactides tethered with polyhedral oligomeric silsesquioxane. Journal of Applied Polymer Science, 115, 1039-1046 (2009). DOI: $10.1002 / a p p .31076$

[38] Ho C-H., Jang G-W., Lee Y-D.: Crystallization of poly(L-lactide-dimethyl siloxane-L-lactide) triblock copolymers and its effect on morphology of microphase separation. Polymer, 51, 1639-1647 (2010).

DOI: $10.1016 /$ j.polymer.2009.11.030

[39] Xu H., Teng C., Yu M.: Improvements of thermal property and crystallization behavior of PLLA based multiblock copolymer by forming stereocomplex with PDLA oligomer. Polymer, 47, 3922-3928 (2006).

DOI: $\underline{10.1016 / \text { j.polymer.2006.03.090 }}$
[40] Brochu S., Prud'homme R. E., Barakat I., Jerome R.: Stereocomplexation and morphology of polylactides. Macromolecules, 28, 5230-5239 (1995).

DOI: 10.1021/ma00119a010

[41] Liao R. G., Yang B., Yu W., Zhou C.: Isothermal cold crystallization kinetics of polylactide/nucleating agents. Journal of Applied Polymer Science, 104, 310 317 (2007).

DOI: $10.1002 /$ app. 25733

[42] Kolstad J. J.: Crystallization kinetics of poly(L-lactide-co-meso-lactide). Journal of Applied Polymer Science, 62, 1079-1091 (1996).

DOI: $10.1002 /($ SICI) 1097-4628(19961114)62:7<1079 $\because$ AID-APP14>3.0.CO;2-1

[43] Ikada Y., Jamshidi K., Tsuji H., Hyon S. H.: Stereocomplex formation between enantiomeric poly(lactides). Macromolecules, 20, 904-909 (1987). DOI: $10.1021 / \mathrm{ma} 00170 \mathrm{a} 034$ 